\title{
Pengaruh Prinsip Technology Acceptance Model (TAM) Terhadap Kepuasan Pelanggan Aplikasi Ojek Online XYZ
}

\author{
Moh Hadi Subowo,M.T.I 1 \\ 1Fakultas Ushuluddin dan Humaniora \\ Universitas Islam Negeri Walisongo Semarang \\ hadi.subowo@walisongo.ac.id
}

\begin{abstract}
The use of the online taxibike XYZ application is based on the Technology Acceptance Model (TAM) theory. The online taxibike XYZ application can be good if it has a good assessment based on the TAM variable. The purpose of this study is to obtain empirical evidence regarding the effect of the TAM principle on customer satisfaction. This study uses a quantitative causal research method to analyze the application of the Technology Acceptance Model (TAM) principle to online taxibike XYZ application customer satisfaction. The instrument in this study used a questionnaire instrument with a closed questionnaire type. The data analysis technique used three tests: data quality test, hypothesis test, and classical assumption test. All variables $\mathrm{x}$, both reliability, flexibility, privacy, accessibility, ease to use, all positively influence customer satisfaction.
\end{abstract}

Key words: Technology Acceptance Model (TAM); Customer Satisfication; online taxibike XYZ application

\begin{abstract}
Abstrak
Penerapan dalam aplikasi ojek online XYZ di latar belakangi oleh teori Technology Acceptance Model (TAM). Aplikasi yang dikembangkan ojek online XYZ bisa disebut layak apabila mengantongi anggapan positif berdasarkan alasan ketepatan variabel TAM. Tujuan utama dari riset ini adalah mendapatkan data yang valid tentang adanya pengaruh prinsip TAM terhadap kepuasan pelanggan. Riset kausal menjadi metode yang digunakan dalam penelitian ini demi menganalisis mengenai penerapan prinsip Technology Acceptance Model (TAM) terhadap kepuasan pelanggan ojek online XYZ. Instrumen yang diterapkan pada riset ini berupa instrumen angket pertanyaan tertutup. Teknik analisis dalam pengolahan data menerapkan tiga uji yakni uji kualitas data, uji hipotesis, serta uji asumsi klasik. Hasil yang diperoleh dari penelitian ini bahwa semua variabel independen, baik reliabilitas, fleksibilitas, keamanan, kemudahan penggunaan, pribadi, serta kemudahan akses bahwa seluruhnya memegang pengaruh yang positif signifikan terhadap variable Y yaitu kepuasan pelanggan.
\end{abstract}

Kata Kunci: Technology Acceptance Model (TAM); Kepuasan pelanggan; Aplikasi ojek online XYZ. 


\section{Latar Belakang}

Meningkatnya strukturisasi di seluruh bidang didorong oleh keadaan dalam hal ekonomi yang kian berkembang. Kesetiaan konsumen terhadap pemakaian produk atau pelayanan yang diberikan oleh perusahaan menjadi tujuan yang harus dicapai agar aspek produktivitas dalam hal kecepatan dan keakuratan bisa terpenuhi (Fu et al., 2015). Supaya tetap bisa berkompetitif perusahaan harus meningkatkan kinerja dalam bidang evolusi teknologi. Melalui dukungan terhadap kebermanfaatan sistem informasi yang dikembangkan oleh perusahaan yang juga termasuk ke dalam investasi sumber daya (F. Davis, 2009). Kumpulan informasi yang telah dikumpulkan kemudian diproses untuk menjadi system yang kemudian dinamakan sistem informasi (Suwarni dan Mayasari, 2011). Pertimbangan akan penarikan keputusan yang dilakukan oleh pimpinan perusahaan akan lebih ringan apabila terdapat informasi yang selaras, terpercaya, mudah ditangkap, dan cepat lewat adanya sistem informasi (Puhakainen \& Siponen, 2010).

Bidang jasa transportasi mengalami kemajuan dalam perkembangan teknologi yang berupa program aplikasi. Pada kota metropolitan selayaknya Jakarta, Suarabaya, Bandung, serta Ibukota provinsi mengalami perkembangan dan berpengaruh terhadap kepastian hukum oleh kemenhub sehingga mengedarkan peraturan Menteri perhubungan ketika menyistemkan mengenai transportasi berbasis online seperti pada Permen Perhub Nomor PM 32 tahun 2016 yang berhubungan dengan pengaturan angkutan orang yang berada di jalan dengan kendaraan umum. Hal ini kemudian dijadikan dasar kemenhub untuk membuat pengaturan tentang aplikasi untuk layanan angkutan umum.

Pangsa pasar transportasi online mengalami persaingan ketat. Baik transportasi online sepeda motor atau mobil mengalami pertambahan baik pedaftaran sebagai driver atau penumpang. Semenjak aplikasi ojek online XYZ mengalami peningkatan pesat dengan jumlah unduhan selama tiga bulan berturut-turut (Lutfi, 2020). Per Januari 2015 aplikasi ini telah di download sebanyak 32.156 kali peningkatan selanjutnya terjadi di bulan februari dengan 81.768 kali, dan pada bulan marett Kembali megalami peningkatan sebesar 131.867 kali. Aplikasi ojek online XYZ berfokus pada kepuasan pelanggan, hal ini kemudian menjadi cerminan dari perusahaan penyedia jasa. Pengguna aplikasi ojek online XYZ masih belum bisa di data dengan pasti dikarenakan penyebaran lokasi.

Selain itu Prasetyo \& Rukiyah (2019) memaparkan data unggulan terkait pengelolaan aplikasi ojek online Indonesia saat ini adalah XYZ. Pengguna aplikasi ojek online XYZ saat ini mencapai $21,6 \%$ dari total jumlah pengguna teknologi di Indonesia. Sementara kompetitornya mencapai 6,4\% pengguna. Pada dewasa ini kepesatan teknologi wajib dioptimalkan oleh perusahaan penyedia jasa transportasi demi meningkatkan produktivitas hasil kerja perusahaan dengan tujuan agar perusahaan tetap kompetitif. Kehandaan teknologi akan memudahkan setiap tugas yang dilakukan oleh karyawan di dalam perusahaan dan memberikan informasi yang berkualitas. Informasi yang berkualitas tersedia dalam bentuk sistem informasi yang baik. Perusahaan besar berinvestasi dalam peningkatan produktivitas dengan menciptakan 
sistem perangkat lunak yang canggih (F. Davis, 2009).

Berkat adanya teknologi yang membentuk system informasi memudahkan karyawan untuk menemukan informasi bermanfaat, relevan, teruji waktu yang dapat membantu mereka dalam fase pengambilan kebijakan (Aryani \& Rosinta, 2010). Aplikasi sendiri merupakan produk yang diproduksi sendiri atau produk olahan yang menghasilkan suatu format informasi (Suwarni dan Mayasari, 2011). Aplikasi bisa dikatakan sebagai kombinasi dari kumpulan perangkat keras, perangkat lunak, komunikasi, dan sumber informasi yang mengumpulkan, memodifikasi, dan menyebarkan informasi dalam kelompok organisasi (Prasetyo \& Rukiyah, 2019). Informasi yang diperoleh dari pengolahan data dapat digunakan untuk membuat perangkat pengambilan keputusan oleh otoritas demi memajukan perusahaan (Aryani \& Rosinta, 2010).

Desain sistem informasi yang diaplikasikan yaitu Technology Acceptance Model - TAM. Desain ini diharapkan bisa membawa nilai positif bagi pengguna ketika menjalankan sistem informasi. Terdapat sebuah teori yang diberi nama Theiory of Reasoned Action - TRA yang merupakan hasil penemuan Davis (Yousafzai et al., 2010) yang menjadi teori pendukung dalam TAM. Penentu utama dalam TAM ada dua yaitu perceived usefulness dan perceived easy of use. Dua penentu tersebut menyebabkan konsumen dapat menggunakan sistem informasi yang dibuat. Dalam penggunaan sistem informasi terdapat sebuah teori yang berfungsi mengetahui kecenderungan pengguna yang lahir berdasarkan gagasan TAM yang dipelopori oleh Davis,
(Noulas et al., 2011). Tujuan adanya model TAM tidak lain adalah membuat kata kunci dari pengguna teknologi informasi bisa dikumpulkan untuk dipakai sebagai bahan evaluasi pengembangan teknologi informasi berikutnya (Noulas et al., 2011). Unsur yang menjadi pendorong sikap individu bisa menjadi bahan pertimbangan mengenai tanggapan dan persetujuan pengguna terhadap pemakaian desain TAM (Liu et al., 2011).a

Selain memberikan layanan pelanggan yang sangat baik, setiap perusahaan telah mengembangkan berbagai aplikasi untuk meningkatkan kinerja, mengurangi biaya, tenaga kerja, dan waktu. Salah satu program yang dibahas dalam penelitian ini adalah program aplikasi ojek online XYZ. Aplikasi ojek online XYZ adalah aplikasi mobile yang memudahkan pengemudi untuk melakukan pemesanan layanan pengantaran. Program aplikasi ojek online XYZ terbuka untuk pengemudi dan pengguna. XYZ mengembangkan sistem informasi berbasis program aplikasi dengan konsep dasar bersumber dari Technology Acceptance Model (TAM) yang dipelopori Fred D. Davis (Lai, 2017). Melalui teori ini respon yang diberikan pengguna bisa dicatat dan direkam. Respon yang dicatat kemudian dianalisis melalui teori Tam untuk dilihat seberapa besar penerimaan yang diberikan oleh pengguna (Pal \& Vanijja, 2020). Adapun dasar yang dijadikan sebagai pedoman program TAM adalah reliabilitas, fleksibilitas, keamanan, kemudahan penggunaan, pribadi, serta kemudahan akses (Lupiyoadi, 2011). Tujuh variable TAM yang bereputasi positif bisa berdampak pada penilaian aplikasi ojek online XYZ yang dikatakan sempurna. 
Pemenuhan terhadap prinsip TAM menjadikan perusahaan bisa mengalami peningkatan terkait system kepuasan pelanggan Perusahaan bisa mendapat kesuksesan jika sistem informasi yang mereka kembangkan terbukti efektif (DeLone \& McLean, 2016). Penelitian DeLone \& McLean dirangkum oleh (Komara \& Ariningrum, 2013) yang mendiskusikan mengenai pengukuran terhadap kepuasan pelanggan jika dilihat dari sisi pengguna yang mengantongi dua poin tahapan yakni pemakaian sistem informasi (system usage) dan kepuasan konsumen terhadap akses informasi (user information satisfatction) apabila pegawai merampungkan job desk yang berhubungan tentang pengolahan data informasi keuangan. Demi mengetahui adanya pengaruh prinsip TAM terhadap kepuasan pelangganmaka penelitian berjudul Pengaruh prinsip Pengaruh Prinsip Technology Acceptance Model (Tam) Terhadap Kepuasan Pelanggan.

\section{Landasan Teori}

\section{Technology Acceptance Model (TAM)}

Berdasarkan Model Perolehan Teknologi yang dipelopori oleh Davis dengan tujuan mengungkapkan perilaku pemakaian komputer (F. D. Davis, 1989), maka lahirlah Theory Reasoned Action (TRA). Dimana TRA tersebut memperhitungkan respons user dengan dasar yang diambil berdasarkan akibat dari dua faktor yaitu "Persepsi Manfaat Dirasakan" serta "Persepsi Mudah Penggunaan". Kesan yang dirasakan oleh user ketika menikmati sebuah sistem aplikasi spesifik yang mampu mendongkrak kinerja dalam pekerjaan sebuah perusahaan. Persepsi Model Penerimaan Teknologi dapat dilihat dalam Gambar

Original Technology Acceptance
Model

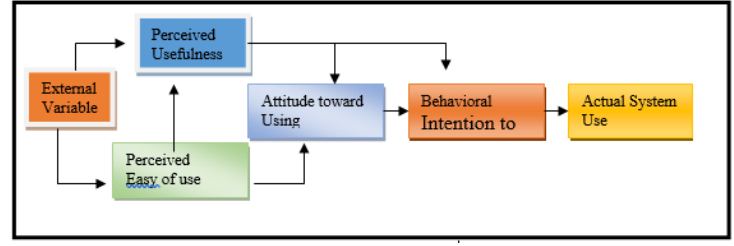

Sumber: (Lai, 2017)

Model Penerimaan Teknologi sudah mengalami perluasan dan pengujian terhadap faktor eksternal yang memiliki perbedaan dalam pemerolehan berbagai aplikasi. Beberapa studi mengenai hal ini memberikan hasil bahwa mereka juga telah memperluas aplikasinya dalam bentuk Internet (Chen et al., 2002; Lin \& Lu, 2000; Rauniar et al., 2014).

Terdapat teori yang sangat berpengaruh jika dihubungkan dengan penerapan formasi teknologi dan informasi yang menjadi hal cukup umum jika dihadapkan dalam berbagai bentuk aplikasi, teori tersebut dinamakan dengan model penerimaan teknologi atau yang disebut Theory Acceptance Model (TAM) dipelopori oleh Fred D. Davis pada tahun 1989. Penjelasan dalam teori ini mencakup bagaimana respon user apabila dihadirkan dengan sebuah teknologi yang benar-benar baru dalam sebuah perusahaan atau organisasi (F. D. Davis, 1989).

Terdapat beberapa kelebihan TAM yang kemudian di paparkan oleh Pratiwi et al., (2020) diantaranya: (1) TAM menjadi alternatif jawaban ketika sebuah system tidak bisa menjawab kebutuhan user, sehingga user kehilangan minat terhadap system informasi yang dibuat; (2) TAM hadir dengan tujuan menjadi dasar teori yang kuat; (3) TAM lolos dari banyak uji riset dengan kesimpulan hasil bahwa TAM termasuk dalam kategori yang positif berdampak; dan (4)TAM menjadi model yang memiliki tampilan sederhana namu valid. Heilesen \& Jensen (2007) menambahkan bahwa TAM juga Mengungkapkan bahwa user dapat 
dengan bebas menentukan teknologi yang akan ia gunakan.

Maka dalam hal ini penerapan sistem informasi harus berkembang dengan memperhatikan Technology Acceptance Model (TAM) yang tentu saja disamping untuk mengoptimalkan kinerja hal ini juga bisa dipakai untuk memperbaiki pandangan masayarakat mengenai penggunaan teknologi. Prinsip Technology menurut (Lupiyoadi, 2013) adalah:

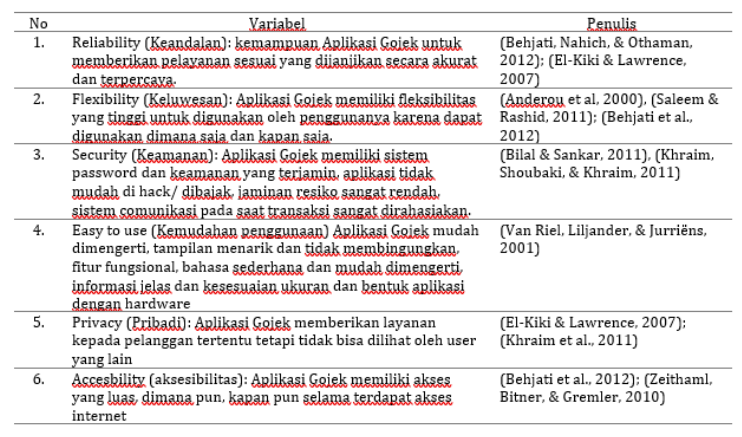

\section{Kepuasan Pelanggan}

Maraknya market place berbasis online mampu meminimalisir keterbatasan jarak dan waktu. Salah satu penentu suksesnya sebuah bisnis online adalah kepuasan pelanggan.

Website merupakan salah satu layanan dalam dunia elektronik yang mewadahi transaksi antara pelaggan dan pemilik jasa/produk Jeong \& Lee (2010). Pelayanan pelanggan menjadi urgensi perusahaan online dibandingkan dengan diskon dan kehadiran sebuah website (Zeithaml et al., 2010).

Bisnis online menjadikan pelanggan dan pemilik jasa/produk tidak bisa berinteraksi secara langsung. Oleh karena itu, keberadaan pelayanan mampu memberikan konsumen kepuasan atas adanya pengalaman yang melebihi ekspektasi mereka. 11 faktor diungkapkan oleh (Parasuraman et al., 1988) mampu mempengaruhi kepuasan pelanggan. Kesebelas factor tersebur diantaranya:

1. Kehandalan, merupakan akurasi pelayanan yang dijanjikan yang berkaitan dengan ketersediaan produk, penditribusian produk, serta informasi dan proses pembayaran)

2. Daya tanggap, Kesediaan untuk memberikan solusi ketika pelanggan mengalami permasalahan ataupun membutuhkan bantuan.

3. Akses, kemudahan untuk melakukan transaksi sesuai keinginan pelanggan tanpa pembatasan jarak dan waktu.

4. Fleksibilitas, kemampuan perusahaan dalam menyediakan berbagai varian layanan mulai dari pembayaran sampai pengembalian produk.

5. Kemudahan navigasi, kemudahan pelanggan dalam menggunakan situs layanan,

6. Efisiensi, Laman berisikan informasi yang dibutuhkan pelanggan.

7. Kepercayaan, kejelasan situs dalam memberikan layanan kepada pelanggan atau disebut juga dengan penilaian pelanggan terhadap pelayanan yang diberikan.

8. Keamanan, merupakan jaminan akun pelanggan untuk tiak mudah diretas oleh hacker.

9. Pengetahuan harga, merupakan penyediaan informasi varian harga ketika pelanggan melakukan transaksi (ongkos kirim, harga kumulatif, harga produk)

10. Estetika situs, visualisasi desain yang menarik minat pelanggan.

11. Kustomisasi, merupakan layanan ekstra sesuai dengan selera pelanggan. 
Kualitas memberikan dorongan khusus bagi para pelanggan untuk menjalin ikatan relasi saling menguntungkan dalam jangka panjang dengan perusahaan. Kepuasan konsumen menjadi asset yang begitu bernilai agar bisnis dapat terus berjalan. Indikator kepuasan konsumen menurut Lupiyoadi, (2013) dapat dillihat pada lima poin utama diantaranya:

1. Melalui kualitas produk yang baik konsumen akan merasa puas.

2. Melalui kualitas pelayanan yang diberikan konsumen akan terpuaskan, khususnya jika menyangkut insustri yang bergerak di bidang jasa.

3. Terdapat pengaruh emosional terhadap konsumen apabila produk yang dipilih konsumen dikagumi oleh orang lai.

4. Relatifitas harga produk menjadi hal yang bisa membuat konsumen beralih menggunakan produk dengan harga yang lebih murah namun tetap berkualitas.

5. Tanpa adanya biaya ekstra konsumen akan merasa lebih nyaman karena tidak memikirkan biaya selain harga produk yang dipilih

Mengenai gagasan kepuasan pelanggan terdapat dua faktor yang cukup berpengaruh, yaitu harapan dan kinerja. Makna dari kinerja berakitan dengan pendapat konsumen mengenai produk setelah digunakan. Sedangkan harapan berkaitan dengan perkiraan yang dimiliki konsumen terhadap suatu barang. Lebih lanjut alur kepuasan pelanggan akan digambarkan pada bagan berikut:

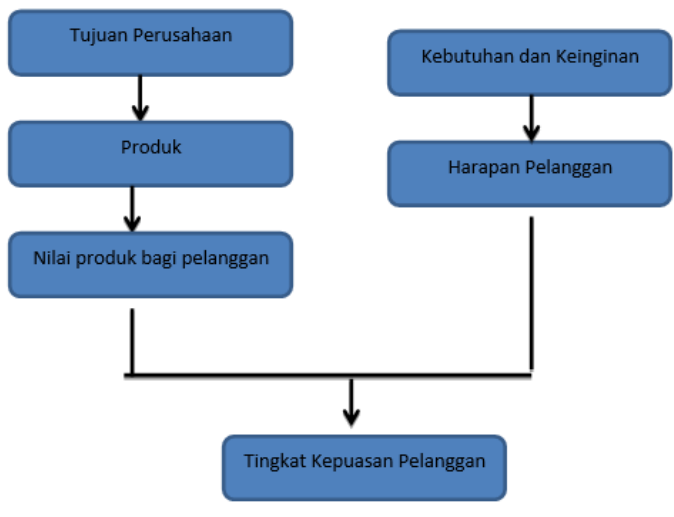

Konsep Kepuasan Pelanggan

Sumber: (Tjiptono, 2006)

Menurut (Zeithaml et al., 2010) penilaian kepuasan klien dapat diambil berdasarkan prinsip berikut:

1. Kualitas layanan < ekspektasi/harapabn, kualitas pelayanan yang lebih kecil dari harapan pelanggan mengindikasikan buruknya kualitas layanan sebuah perusahaan. Hal ini mengakibatkan kekecewaan pelanggan disebabkan karena ekspektasi yang diharapkan pada perusahaan tidak sesuai dengan harapan pelanggan.

2. Kualitas layanan=ekspektasi/harapan, kesesuaian kualitas layanan dengan ekspektasi pelanggan memberikan makna yang tidak istimewa. Artinya, pelayanan berada di level tengah dengan kualitas yang belum mencapai istimewa dan tidak terlalu buruk.

3. Kualitas layanan > ekspektasi/harapan, kualitas layanan yang lebih besar dari ekspektasi pelanggan memberikan keuntungan yang mengarah pada kepuasan pelanggan. Hal ini memberikan rasa puas pada pelanggan karena pelayanan perusahaan lebih dari sekedar sesuai kebutuhan, 
sehingga pelanggan merasa lebih diuntungkan dengan keadaan ini.

Kepuasan diartikan sebagai perasaan yang dimiliki pelanggan setelah mendapatkan suatu layanan yang dirasa sesuai dengan ekspektasinya (Kotler, 2011). Dalam persaingan bisnis online yang semakin ketat, faktor kepuasan pelanggan menjadi perhatian yang serius. Menurut.

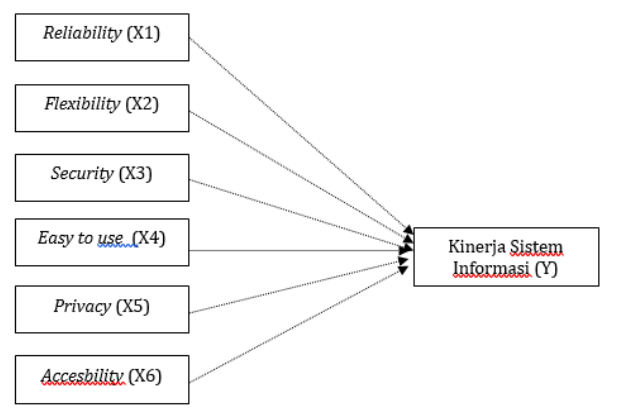

\section{Hasil Analisa}

Pengaruh atau ketergantungan antara variabel independen $(\mathrm{X})$ dan variabel dependen (Y) dapat dihitung dengan analisis regresi berganda. Agar hasil data semakin valid maka pengolahan data dilakukan menggunakan SPSS versi 17.00 dengan bantuan program komputer dan tabel coefficient.

Tabel 4.17. Pengujian Regresi Berganda

\begin{tabular}{cccc}
\hline Variable & Beta & sig & Keterangan \\
\hline X1_Reliability & 0.411 & 0.022 & Positifigignifikan \\
\hline X2_Fleksibilitas & 0.352 & 0.013 & Positiff signifikan \\
\hline X3_Privacy & 0.537 & 0.000 & Positif signifikan \\
\hline X4_Aksesibilitas & 0.316 & 0.012 & Positif signifikan \\
\hline X5_Ease_to_navigation & 0.210 & 0.000 & Positif signifikan \\
\hline X6_Efisiensi & 0.304 & 0.010 & Positif signifikan \\
\hline X7_Security & 0.023 & 0.018 & Positif signifikam \\
\hline
\end{tabular}

Hasil uji reliabilitas (X1) terkait kepuasan pelanggan menghasilkan pengaruh positif yang signifikan. Hal ini terlihat dari nilai $\beta(0,411)$ dan nilai sig. $(0,022<0,05)$, serta peningkatan nilai dan kestabilan variabel independen lain sebesar $1 \%$ yang berdampak pada peningkatkan kepuasan pelanggan (Y) sebesar 0,411. Semakin reliabel maka semakin baik dampaknya terhadap kepuasan pelanggan.

Hasil uji Fleksibilitas (X2) terkait kepuasan pelanggan menghasilkan pengaruh positif yang signifikan. Hal ini terlihat dari angka $\beta(0.352)$ dan nilai sig. $(0.013<0.05)$ serta peningkatan nilai dan kestabilan variabel independen lain sebesar 1\%, yang berdampak pada peningkatkan kepuasan pelanggan (Y) sebesar 0.352. Semakin fleksibel maka semakin baik dampaknya terhadap kepuasan pelanggan.

Hasil uji Privacy (X3) terkait kepuasan pelanggan menghasilkan pengaruh positif yang signifikan. Hal ini terlihat dari nilai $\beta$ (0.537) dan angka sig. $(0.000>0.05)$ serta peningkatan nilai dan kestabilan variabel independen lain sebesar 1\%, yang berdampak pada peningkatkan kepuasan pelanggan (Y) sebesar 0.537. Semakin aman aplikasi yang ditawarkan maka semakin baik dampaknya terhadap kepuasan pelanggan.

Hasil uji Aksesibilitas (X4) terkait kepuasan pelanggan menghasilkan pengaruh positif yang signifikan. Hal ini terlihat dari angka $\beta(0.316)$ dan angka sig. $(0.012>0.05)$ serta peningkatan nilai dan kestabilan variabel independen lain sebesar 1\%, yang berdampak pada peningkatkan kepuasan pelanggan (Y) sebesar 0.316. Semakin mudah diakses maka semakin baik dampaknya terhadap kepuasan pelanggan.

Hasil uji Ease to navigation (X5) terkait kepuasan pelanggan menghasilkan pengaruh positif yang signifikan. Hal ini terlihat dari nilai $\beta(0.210)$ dan angka sig. $(0.000>0.05)$ serta peningkatan nilai dan kestabilan variabel independen lain sebesar 1\%, yang berdampak pada peningkatkan kepuasan pelanggan (Y) sebesar 0.210. Semakin mudah 
navigasinya maka semakin baik dampaknya terhadap kepuasan pelanggan.

Hasil uji efisiensi (X6) terkait kepuasan pelanggan menghasilkan pengaruh positif yang signifikan. Hal ini terlihat dari nilai $\beta$ (0.304) dan nilai sig. $(0.010<0.05)$ serta peningkatan nilai dan kestabilan variabel independen lain sebesar $1 \%$, yang berdampak pada peningkatkan kepuasan pelanggan (Y) sebesar 0.304. Semakin efisien maka semakin baik dampaknya terhadap kepuasan pelanggan.

Hasil uji Security (X7) terkait kepuasan pelanggan menghasilkan pengaruh positif yang signifikan. Hal ini terlihat dari nilai $\beta$ (0.023) dan angka sig. 0.018>0.05; serta peningkatan nilai dan kestabilan variabel independen lain sebesar 1\%, yang berdampak pada peningkatkan kepuasan pelanggan $(\mathrm{Y})$ sebesar 0.023. Semakin aman maka semakin baik dampaknya terhadap kepuasan pelanggan.

\section{Uji $\mathrm{f}$}

Dari hasil uji $\mathrm{F}$ yang telah dilakukan didapatkan Statistik f sebesar 12,214 dan memiliki nilai 0,000, dimana hasil yang didapatkan lebih besar dari tabel $\mathrm{F}$ $(2,14)$ dengan $n$ sebesar 30 . Hal ini menghasilkan kesimpulan bahwa Ho ditolak sehingga variable reability, fleksibilitas, Privacy, aksestabilitas, ease to use mendapatkan angka yang signifikan kepada kepuasan pelanggan.

\section{Koefisien determinasi R2}

Bersumber dari hasil enumerasi didapat nilai R2 (R square) 0.795 atau menghasilkan persentase sebesar (79\%). Hal ini membuktikan bahwa nilai persentase mempengaruhi seluruh variable. $21 \%$ lainnya disebabkan oleh factor lain yang tidak dijelaskan dalam penelitian ini.

\section{Pembahasan}

Lupiyoadi (2011) mengartikan reliabilitas sebagai usaha memberikan layanan yang tepat serta handal. Mendukung pendapat ini, Ratnadi \& Suprianto (2016) menerangkan jika keandalan merupakan pengaturan pemanfaatan keadaan daerah maupun situasi periode, serta produk maupun servis yang sanggup meraih standar fungsional yang dibutuhkan. Keluwesan menggambarkan suatu sifat dari suatu produk teknologi aplikasi data yang mempunyai penanda semacam elastisitas. Hal ini menjadikan aplikasi ojek online XYZ lebih mudah dipakai kapan pun serta dimanapun, akibatnya mempermudah konsumen jika sewaktu waktu ingin melakukan transaksi (Behjati, Nahich, 2012).

E- Tax mempunyai keluwesan yang besar guna dipakai konsumen, sebab bisa dipakai dimanas aja serta kapan saja khususnya pada saat seseorang tengah bepergian. Pergerakan masyarakat yang besar sangat berakibat positif untuk pemakaian e- Tax sebab penggunaannya mempercepat durasi serta gampang diakses. Sokongan network yang semakin baik setiap mampu menambah minat masyarakat dalam untuk memakai e- Tax yang terus menjadi besar oleh kalangan masyarakat. Pertumbuhan e- Tax mampu merubah cara transaksi yang tadinya ribet dan sukar menjadi lebih efisien disebabkan adanya kesempatan untuk melakukan transaksi tanpa keterbatasan ruang dan waktu, artinya transaksi bisa dilakukan dimana saja dan kapan saja. Hal ini selaras dengan hasil pengujian yang membuktikan bahwa system informasi 
juga diakibatkan karena adanya fleksibilitas layanan.

Security atau keamanan merupakan bagian dari piranti yang berfungsi mendeteksi gangguan yang bersifat asing pada sistem transaksi yang menggunakan E- Tax. Luqman, Septama, Clara, Wlw, \& Hamidan (2018) memberikan sebagian penunjuk dari system keamanan dengan layanan transaksi yang kredibel, dan handal dilengkapi prasyarat kerahasiaan berupa sandi sehingga akun yang dimiliki klien tidak mudah diganggu, dikenai pembajakan oleh hacker serta data transaksi yang hanya bisa diakses pengguna (bersifat rahasia).

Hal ini membuktikan bahwa system keamanan turut berpengaruh kemampuan system informasi. Apabila aplikasi ojek online bisa memberikan kepercayaan terhadap keamanan pengguna atau user maka tingkat kepuasan pelanggan terkait aplikasi juga bisa meningkat. User pada dasarnya seorang individu yang membutuhkan jaminan keamanan, aplikasi sering kali membutuhkan data diri pengguna baik driver maupun penumpang. Jika data ini disalahgunakan sehingga membuat ketidaknyamanan maka kepercayaan pelanggan terhadap aplikasi yang dikeluarkan juga berkurang.

Suatu technology ataupun aplikasi bisa digunakan secara gampang bila mempunyai karakter yang mempunyai nilai kenyamanan yang hendak mempengaruhi positif tingkat pemakaian serta kebahagiaan klien. aplikasi bisa dibilang mudah dipakai bila mempunyai karakteristik semacam navigasi mudah dipahami, tampilan menarik serta tidak membingungkan, fitur fungsional, bahasa simpel serta gampang dipahami, data nyata serta kesesuaian dimensi serta wujud aplikasi dengan perangkat keras. Dengan aplikasi yang gampang dipakai sehingga pekerjaan dan permasalahan klien dapat terselesaikan secara efektif dan efisien (Van riel Allard C.R. et al, 2004). Pengujian yang dilakukan menunjukkan bahwa kemudahan navigasi memberikan efek yang sifatnya positif signifikan pada kepuasan klien.

Privacy adalah layanan pribadi antara perusahaan yang memungkinkan klien dan badan usaha mengakses informasi tentang pelanggan mereka. Informasi ini mencatat detail akun yang dipegang oleh pelanggan, nilai pelanggan, kapan pelanggan pergi, dan dengan siapa pelanggan membuat pesanan. Data ini disimpan pada data yang terjaga dan dapat mengingatkan pengguna bahwa itu adalah bukti transaksi yang dapat digunakan untuk tujuan tertentu. Dalam sifat transaksi yang sensitif, sistem menyimpan data pengguna dengan tujuan memastikan data tidak tersebar luas (Susilo, 2016).

Kerahasiaan (privacy) sebagai salah satu variable terbukti memberikan efek yang bermakna positif pada performa informasi. Kemudahan layanan salah satu bentuk fasilitas yang diberikan dilihat dari besarnya layanan perbankan perkantoran. Akses adalah bagian urgent berasal dari semua level sarana yang dipersembahkan kepada klien keuangan. Selama Anda memiliki akses ke internet, Anda dapat memiliki akses ekstensif ke mana pun, kapan pun. Kegiatan ini dapat diperpanjang jika tidak ada masalah selama pengoperasian (Sunandar \& Satar, 2016).

Selain itu, dapat dilihat bahwa pengguna memiliki tingkat akses yang tinggi dalam menyelesaikan pekerjaan pengguna, karena pengguna dapat dengan cepat 
dan mudah memasuki situs atau aplikasi (Febriyanto et al., 2019). Berdasarkan hasil percobaan diketahui bahwa aksesibilitas berpengaruh positif signifikan terhadap kepuasan pelanggan. Tahapan sistem informasi sering kali melibatkan entri data, yang diproses dalam format berbasis data, yang kemudian dimasukkan kembali ke dalam rekomendasi dan diulang jutaan kali. Lebih lanjut Almilia \& Briliantien (2007) menerangkan bahwa aksesibilitas diartikan sebagai kelompok bagian system yang bersifat visual dan nonvisual yang keduanya saling bertautan untuk mengkonversi data guna menciptakan sebuah informasi bermanfaat.

Beberapa factor terbukti memberi pengaruh terhadap kepuasan customer. Penelitian yang dilakukan oleh Devi dan Suartana (2014) menyebutkan, computer efikasi diri serta kepercayaan memberikan efek yang positif terhadap kemudahan penggunaan, sedangkan individualitas tidak berpengaruh pada keduanya. Hasilnya lebih besar dari tabel $F$ (2.14) sebesar $n 30$ untuk Ho penolakan, yang dapat disimpulkan dengan keandalan, fleksibilitas, privasi, aksesibilitas, kemudahan penggunaan dan hasil penting yang diperoleh dari kepuasan pelanggan dan seluruh variable independent menimbulkan efek yang bersifat positif signifikan.

\section{Kesimpulan}

Hasil penelitian menyimpulkan bahwa terdapat pengaruh positif yang signifikan dari variabel Reliabilitas, Fleksibilitas, kebaikan, Efisiensi Privasi, Kemudahan navigasi, dan Keamanan terhadap kepuasan pelanggan(Y). Secara bersama-sama variabel Reliabilitas, Fleksibilitas, kebaikan, Efisiensi Privasi, Kemudahan navigasi, dan Keamanan memiliki pengaruh positif dan signifikan terhadap kepuasan pelanggan. Hal ini membuktikan bahwa aplikasi ojek online XYZ memeuhi semua variable TAM. Pengguna bisa menerima kehadiran aplikasi ini dan memberikan respons yang positif signifikan. Kepuasan pelanggan pada aplikasi ini akan menjadikan trust kepada perusahaan meningkat. 


\section{REFERENCES}

Almilia, L. S., \& Briliantien, I. (2007). Faktor-Faktor Yang Mempengaruhi Kinerja Sistem Informasi Akuntansi Pada Bank Umum Pemerintah Di Wilayah Surabaya Dan Sidoarjo. Jurnal STIE Perbanas Surabaya.

Aryani, D., \& Rosinta, F. (2010). Pengaruh kualitas layanan terhadap kepuasan pelanggan dalam membentuk loyalitas pelanggan. Jurnal Ilmu Administrasi Dan Organisasi.

Behjati, Nahich, O. (2012). Interrelation between E-service Quality and Esatisfaction and Loyalty. Journal European Journal of Business and Management, 4(9).

Chen, M. Y., Kiciman, E., Fratkin, E., Fox, A., \& Brewer, E. (2002). Pinpoint: Problem determination in large, dynamic internet services. Proceedings of the 2002 International Conference on Dependable Systems and Networks. https://doi.org/10.1109/DSN.2002.1029005

Davis, F. (2009). Perceived Usefulness Perceivc-Ease of Use, and User Acceptance of Information Technology. Management Information Systems Quarterly, 319-342.

Davis, F. D. (1989). Davis 1989.pdf. MIS Quarterly.

DeLone, W. H., \& McLean, E. R. (2016). Information Systems Success Measurement. Foundations and Trends® in Information Systems. https://doi.org/10.1561/2900000005

Febriyanto, E., Handayani, I., \& Suprayogi, D. (2019). Aplikasi Sistem Penilaian Penguji Berbasis YII Framework Sebagai Media Input Nilai Mahasiswa Sidang Tugas Akhir Dan Skripsi Pada Perguruan Tinggi. CSRID (Computer Science Research and Its Development Journal).

Fu, Z., Sun, X., Liu, Q., Zhou, L., \& Shu, J. (2015). Achieving efficient cloud search services: Multi-keyword ranked search over encrypted cloud data supporting parallel computing. IEICE Transactions on Communications. https://doi.org/10.1587/transcom.E98.B.190

Heilesen, S. B., \& Jensen, S. S. (2007). Designing for networked communications: Strategies and development. In Designing for Networked Communications: Strategies and Development. https://doi.org/10.4018/978-1-59904-069-1

Jeong, Y., \& Lee, Y. (2010). A study on the customer satisfaction and customer loyalty of furniture purchaser in on-line shop. Asian Journal on Quality. https://doi.org/10.1108/15982681011075952

Komara, A., \& Ariningrum, H. (2013). Analisis Faktor-Faktor Yang Mempengaruhi Kinerja Sistem Informasi Akuntansi. Jurnal Riset Akuntansi Dan Manjemen.

Kotler, P. \& K. L. K. (2011). Manajemen pemasaran jilid 1, edisi Ketiga belas, Terjemahan Bob Sabran. Jakarta: Erlangga. 
Lai, P. (2017). THE LITERATURE REVIEW OF TECHNOLOGY ADOPTION MODELS AND THEORIES FOR THE NOVELTY TECHNOLOGY. Journal of Information Systems and Technology Management. https://doi.org/10.4301/s1807-17752017000100002

Lin, J. C. C., \& Lu, H. (2000). Towards an understanding of the behavioural intention to use a web site. International Journal of Information Management. https://doi.org/10.1016/S0268-4012(00)00005-0

Liu, F., McShea, W. J., Garshelis, D. L., Zhu, X., Wang, D., \& Shao, L. (2011). Human-wildlife conflicts influence attitudes but not necessarily behaviors: Factors driving the poaching of bears in China. Biological Conservation. https://doi.org/10.1016/j.biocon.2010.10.009

Lupiyoadi. (2011). Manajemen Pemasaran Jasa Teori dan Praktik. In Salemba Empat.

Lupiyoadi, R. (2013). Manajemen Pemasaran Jasa: Berbasis Kompetensi Edisi 3. Penerbit Salemba.

Luqman, M., Septama, M., Clara, V., Wlw, T., \& Hamidan, R. (2018). Analisis Perbandingan Mekanisme Enkripsi Data Pada Teknologi Low Power Wide Area (Lpwa) Network: Lora Dan Sigfox. Informatika Mulawarman : Jurnal Ilmiah Ilmu Komputer (JIM).

Lutfi, H. (2020). GO-JEK: REGULATORY RESTRICTIONS AND LOCAL WISDOM'S CHALLENGERS FACED BY THE UNICORN. JWM (Jurnal Wawasan Manajemen).

Noulas, A., Scellato, S., Mascolo, C., \& Pontil, M. (2011). An Empirical Study of Geographic User Activity Patterns in Foursquare. Proceedings of the Fifth International AAAI Conference on Weblogs and Social Media. https://doi.org/papers3://publication/uuid/557455DB-AC4A-4C73-968A31E7A663BC4E

Pal, D., \& Vanijja, V. (2020). Perceived usability evaluation of Microsoft Teams as an online learning platform during COVID-19 using system usability scale and technology acceptance model in India. Children and Youth Services Review. https://doi.org/10.1016/j.childyouth.2020.105535

Parasuraman, a, Zeithaml, V. a, \& Berry, L. L. (1988). SERQUAL: A Multiple-Item scale for Measuring Consumer Perceptions of Service Quality. In Journal of Retailing. https://doi.org/10.1016/S0148-2963(99)00084-3

Prasetyo, I. A., \& Rukiyah, R. (2019). Literasi Informasi Pengendara Ojek Online (Go-Jek) Tembalang Semarang Saat Bertugas. Jurnal Ilmu Perpustakaan.

Pratiwi, S. D., Wiyono, \& Lalu, H. (2020). Perancangan Sistem Pengelolaan Risiko Menggunakan Mockup Website Dan Analisis Technology Acceptance Model (tam) Di Cv. Barokah Abadi. Proceedings of Engineering.

Puhakainen, P., \& Siponen, M. (2010). Improving employees' compliance through information systems security training: An action research study. MIS Quarterly: Management Information Systems. https://doi.org/10.2307/25750704 
Ratnadi, \& Suprianto, E. (2016). Pengendalian Kualitas Produksi Menggunakan Alat Bantu Statistik (Seven Tools) Dalam Upaya Menekan Tingkat Kerusakan Produk. Indept.

Rauniar, R., Rawski, G., Yang, J., \& Johnson, B. (2014). Technology acceptance model (TAM) and social media usage: An empirical study on Facebook. Journal of Enterprise Information Management. https://doi.org/10.1108/JEIM-04-2012-0011

Sunandar, H. S., \& Satar, M. (2016). Tinjauan Tentang Proses Recruitment Tenaga Kerja Di Kantor Pusat Pt. Y Bandung. Indept.

Susilo, G. (2016). Keamanan Basis Data Pada Sistem Informasi Di Era Global. Jurnal TRANSFORMASI.

Suwarni dan Mayasari. (2011). Pengaruh Kualitas Produk dan Harga Terhadap Loyalitas Melalui Kepuasan Konsumen. Jurnal Ekonomi Bisnis, 16(1).

Tjiptono, F. (2006). Manajemen Jasa. In Andi,Yogyakarta.

Van riel Allard C.R. et al. (2004). Online Travel Service Quality Toward Delighted And Loyal. Total Quality Management, 15(4), 75-493.

Yousafzai, S. Y., Foxall, G. R., \& Pallister, J. G. (2010). Explaining internet banking behavior: Theory of reasoned action, theory of planned behavior, or technology acceptance model? Journal of Applied Social Psychology. https://doi.org/10.1111/j.15591816.2010.00615.x

Zeithaml, V. A., Bitner, M. J., \& Gremler, D. D. (2010). Services Marketing Strategy. In Wiley International Encyclopedia of Marketing. https://doi.org/10.1002/9781444316568.wiem01055 
This page intentionally left blank.

92 | WJIT : Walisongo Journal of Information Technology - Vol.2 No. 2 (2020) 